\title{
Kernos
}

Revue internationale et pluridisciplinaire de religion grecque antique

$4 \mid 1991$

Varia

\section{Daraki, Une religiosité sans Dieu}

\section{André Motte}

\section{OpenEdition \\ Journals}

Édition électronique

URL : http://journals.openedition.org/kernos/321

DOI : 10.4000/kernos.321

ISSN : 2034-7871

\section{Éditeur}

Centre international d'étude de la religion grecque antique

\section{Édition imprimée}

Date de publication : 1 janvier 1991

Pagination : 334-336

ISSN : 0776-3824

Référence électronique

André Motte, « M. Daraki, Une religiosité sans Dieu », Kernos [En ligne], 4 | 1991, mis en ligne le 11 mars 2011, consulté le 24 septembre 2020. URL : http://journals.openedition.org/kernos/321 ; DOI : https:// doi.org/10.4000/kernos.321 
paganisme et du christianisme en Laconie durant l'antiquité tardive (chap. 9, p. 120-126). Avec un remarquable esprit de synthèse, l'A. présente ce conflit tel que le révèlent principalement les sources épigraphiques et archéologiques et examine la relation entre le déclin du paganisme et la disparition d'institutions sociales et politiques. Après un épilogue sur Sparte depuis la fin du monde antique jusqu'au moyen âge (p. 213), où il est très brièvement question des édifices et des églises paléo-chrétiennes de la ville, suit un premier appendice reprenant les monuments de la Sparte romaine (p. 216-225). Ils y sont classés par ordre alphabétique et accompagnés d'une référence aux sources épigraphiques et aux rapports archéologiques; parmi les diverses sortes de constructions figurent les autels, les sanctuaires, les portiques ainsi que les cimetières de la ville. L'ouvrage compte encore trois appendices (celui des magistrats, celui des fonctionnaires et celui des agonistai étrangers, p. 226-233), ainsi qu'une bibliographie qui, quoique sélective, comprend presque l'ensemble des études les plus importantes (ou les plus récentes) sur la Sparte hellénistique et romaine (p. 268-289). Un index analytique (p. 291-304) termine cet ouvrage qui nous semble réellement constituer un instrument de travail de premier ordre pour le chercheur qui se consacre non seulement à Sparte mais encore au monde gréco-romain dans son ensemble.

Ioannis LOUCAS (Athènes)

Maria DARAKI, Une religiosité sans Dieu. Essai sur les stö̈ciens d'Athènes et saint Augustin, Paris, Éditions La Découverte, 1989, 223 p., 1 vol. $13,5 \times 22 \mathrm{~cm}$. (Armillaire).

Le titre principal ne concerne assurément que le stoïcisme, et c'est à confronter cette philosophie, dans son radicalisme originel, avec la théologie de l'auteur des Confessions que s'emploie ce brillant essai. En dépit d'une inspiration religieuse et individualiste qui fait leur originalité commune, ces deux visions de l'homme n'en marquent pas moins le plus grand écart entre la pensée antique et le christianisme. D'un côté, on sacralise la nature de part en part et on en fait la source de toutes les valeurs; l'actualisation de celles-ci fait du sage un hommedieu. De l'autre, on tient la nature pour profane et pour indifférente au salut; ainsi livré à son moi, l'homme éprouve devant Dieu une totale impuissance. Dans ces expressions anciennes de l'individualisme, l'A. discerne une préfiguration de deux conceptions que la modernité, au terme d'un processus de laïcisation, engendrera successivement, celle du surhomme, celle ensuite du sujet singulier. L'ouvrage se termine par une réflexion sur l'actuel "retour du religieux" et sur sa possible transformation en des formes plus adaptées, à présent que l'action cosmique de l'homme moderne est devenue plus consciente de 
l'hybris technologique qui a caractérisé son essor. L'exemple du stoïcisme mérite encore à cet égard d'être médité : «La dernière grande philosophie de la Grèce a préparé le passage du religieux mythique, qui aujourd'hui s'essouffle, au sentiment de la sacralité du monde qui est sans doute notre horizon».

C'est dire la portée philosophique, discutable assurément, mais stimulante pour la réflexion, que l'A. entend donner à son étude. La plus grande partie de celle-ci est cependant consacrée à une exégèse du stoïcisme ancien développée à la lumière du contexte politique et social qui l'a vu naitre et aussi du riche héritage culturel qu'il assume en le radicalisant et qui en fait l'un des courants de pensée les plus représentatifs de l'Antiquité.

L'accent est mis tout d'abord sur la composante cynique du stoïcisme, avec sa dépréciation du "civilisé" et sa manière typique de confondre le naturel et le sacré, deux traits qui rappellent le dionysisme; l'A. prolonge et complète sur ce point certaines observations de M. Detienne. La conception mystique du theios anèr se reconnaît aussi dans la figure du sage stoïcien, convié à une sorte d'exploit spirituel, mais elle se voit intégrée dans un système purement moniste. L'opposition sans intermédiaire entre le sage et le vilain porte ellemême la marque d'anciens codes religieux dont témoigne déjà le mythe hésiodique des races. Mais c'est, plus encore, la conception stoïcienne de la physis qui véhicule un legs de la pensée religieuse la plus ancienne. L'A. y discerne l'image, désormais rationalisée et universalisée, de l'antique déesse Terre, laquelle n'engendre pas seulement la vie, mais tous les autres biens, la connaissance et la justice en particulier. La nature englobante des philosophes du Portique est elle aussi la norme unique et suprême des valeurs; elle n'est plus une déesse anthropomorphe, mais elle n'en est pas moins corporelle et divine.

Par ces références aux traditions religieuses, l'A réussit à éclairer certains aspects, parfois déroutants, du stoïcisme ancien, qu'il s'agisse de la physique et de la psychologie, de l'éthique et de la politique, et même de la logique : «le logos qui donne accès à la vérité est une raison enthousiaste qui appartient à l'histoire de la vérité révélée» (p.151). On voit quelle est l'ampleur de la trajectoire parcourue, mais un peu vite peut-être pour aborder tant de questions complexes et convaincre à tout coup le lecteur. Un essai de ce genre évite difficilement les raccourcis simplificateurs. Peut-on, par exemple, présenter Platon comme un grand «déviant» dans cette culture grecque traditionnelle et arguer de son dualisme et de son idéalisme pour dire qu'avec lui «le divin déserte la nature» (p. 148). C'est oublier qu'après le Phédon vient le Phèdre, avec sa valorisation de la beauté sensible, c'est oublier aussi les efforts déployés par Platon pour fonder une religion cosmique. Au demeurant, le stoïcisme ancien se laisse à maints égards interpréter à la lumière 
du platonisme : son monisme panlogique engendre une forme exacerbée d'idéalisme qui détourne, bien plus que chez Platon, de la considération des réalités concrètes et de l'expérience du sacré qu'elles peuvent susciter.

Bien des pistes nouvelles que trace cet intéressant essai n'en méritent pas moins d'être prises en compte et poursuivies.

\section{André MOTTE (Liège)}

Bernard DEFORGE, Le commencement est un dieu. Un itinéraire mythologique, Paris, Les Belles Lettres, 1990, 1 vol., 189 p. (Coll. Vérité des mythes). ISBN 2-251-32416-X.

Le lecteur à qui est familière l'abondante industrie du mythe aura peut-être le sentiment du déjà vu s'il se contente de parcourir en diagonale ce petit volume au titre enchanteur; il est vrai que par le choix du sujet déjà - on sait combien est à la mode ces temps-ci la mythologie -, l'A. est amené à pratiquer à son tour l'art de dire différemment les mêmes choses. Mais il le fait avec une certaine originalité et le désir évident de provoquer, si bien qu'à la fin, tout en se disant que cette matière lui était bien connue, le lecteur ne peut s'empêcher de trouver qu'au fond, l'entreprise de Bernard Deforge a un côté subversif! Chose certaine, son intention de proposer au lecteur un mode d'initiation à la mythologie» est claire. Comme en toute initiation, il faudra vivre l'épreuve pour triompher : le lecteur ne le regrettera pas.

Si l'on accepte de ne pas perdre de vue le but que s'était mis en tête l'A. en rédigeant ce court volume et en l'inscrivant dans la collection qu'il dirige aux Éditions des Belles Lettres, on ne peut que se réjouir du parti-pris qu'il adopte, dans ce qu'il qualifie d'«itinéraire mythologique» : il entend nous ramener non plus au miracle grec, mais à une mythologie des origines dont les racines profondes appartiennent au monde indo-européen, mais plus encore - c'est là sa thèse - à l'aire méditerrannéenne et au Proche-Orient tout entier. Hésiode sera son guide dans cette démonstration.

Une première partie, joliment appelée "l'entonnoir du temps" (p. 9 à 55), s'attache à situer la Grèce dans l'histoire (et même dans la préhistoire) du monde, la civilisation grecque devenant le point de convergence et de synthèse de ces multiples approches, lancées en un style télégraphique qui les fait paraître plus touffues qu'elles ne le sont. En réalité, le texte est composé de fiches signalétiques, savantes et bien fouillées, mais souvent trop synthétiques : ne livrant que des pistes, elles contribuent, par leur accumulation quand même judicieusement dosée, à convaincre le lecteur de l'à-propos de la thèse défendue par l'A.

L'avalanche des notations oblige le lecteur à se laisser emporter dans cet entonnoir du temps. Il n'y peut échapper! Du même coup, 